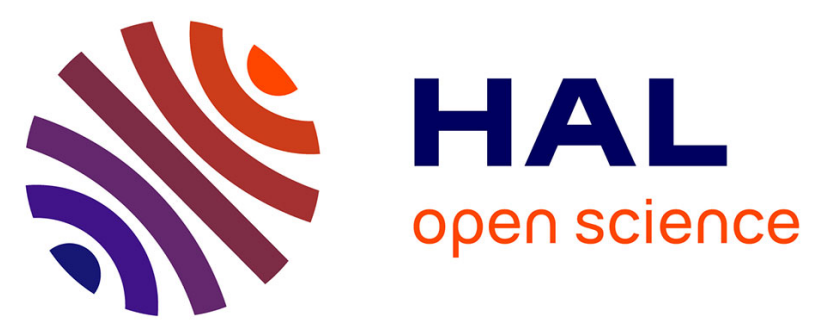

\title{
Non-fatal suicidal behaviours in French Polynesia: Results of the WHO/START study and its implications for prevention
}

Stéphane Amadéo, Kairi Kõlves, Aurelia Malogne, Moerani Rereao, Patrick Favro, Ngoc Lam Nguyen, Louis Jehel, Diego de Leo

\section{To cite this version:}

Stéphane Amadéo, Kairi Kõlves, Aurelia Malogne, Moerani Rereao, Patrick Favro, et al.. Non-fatal suicidal behaviours in French Polynesia: Results of the WHO/START study and its implications for prevention. Journal of Affective Disorders, 2016, 189, pp.351 - 356. 10.1016/j.jad.2015.09.042 . hal-01628699

\section{HAL Id: hal-01628699 \\ https://hal.science/hal-01628699}

Submitted on 4 Nov 2017

HAL is a multi-disciplinary open access archive for the deposit and dissemination of scientific research documents, whether they are published or not. The documents may come from teaching and research institutions in France or abroad, or from public or private research centers.
L'archive ouverte pluridisciplinaire HAL, est destinée au dépôt et à la diffusion de documents scientifiques de niveau recherche, publiés ou non, émanant des établissements d'enseignement et de recherche français ou étrangers, des laboratoires publics ou privés. 
Research report

\title{
Non-fatal suicidal behaviours in French Polynesia: Results of the WHO/START study and its implications for prevention
}

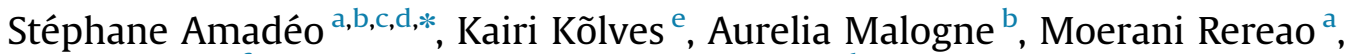 \\ Patrick Favro ${ }^{\mathrm{f}}$, Ngoc Lam Nguyen ${ }^{\mathrm{g}}$, Louis Jehel ${ }^{\mathrm{c}, \mathrm{h}}$, Diego De Leo ${ }^{\mathrm{e}}$ \\ ${ }^{a}$ Centre Hospitalier de Polynésie Française (CHPF), Tahiti, French Polynesia \\ ${ }^{\mathrm{b}}$ Centre de Prévention du Suicide de Polynésie Française (CPSPF), Tahiti, French Polynesia \\ ' Unité Inserm U1178, Paris, France \\ ${ }^{\mathrm{d}}$ Centre des Nouvelles Etudes sur le Pacifique (CNEP), Université de Nouvelle Calédonie, New Caledonia \\ ${ }^{\mathrm{e}}$ Australian Institute for Suicide Research and Prevention (AISRAP), National Centre of Excellence in Suicide Prevention, WHO Collaborating Centre for \\ Research and Training in Suicide Prevention, Griffith University, Brisbane, Australia \\ ${ }^{\mathrm{f}}$ Université de Polynésie Française (UPF), Tahiti, French Polynesia \\ ${ }^{g}$ Direction de la Santé Publique de Polynésie Française, Tahiti, French Polynesia \\ ${ }^{\mathrm{h}}$ Centre Hospitalier Universitaire, Martinique, France
}

\section{A R T I C L E I N F O}

\section{Article history:}

Received 26 March 2015

Received in revised form

7 July 2015

Accepted 21 September 2015

Available online 25 September 2015

Keywords:

Non-fatal suicidal behaviour

Suicide prevention

French Polynesia

Pacific Islands

\begin{abstract}
A B S T R A C T
Objectives: This is the first research article examining non-fatal suicidal behaviours (NFSB) in French Polynesia. The study was conducted in the frames of the WHO/START Study in 2008-2010. The main objective of the investigation was to obtain reliable data in order to develop evidence-based suicide prevention strategies.

Method: Interviews with people presenting with NFSB at the Emergency Department (ED) of the French Polynesia Hospital (CHPF) were conducted by emergency and psychiatry departments' staff examining socio-demographic and clinical information and motives triggering suicidal behaviour. Odds ratios and rate ratios with $95 \%$ confidence intervals were calculated.

Results: There were 556 presentations of NFSB by 515 persons at the ED of CHPF (ratio 1.08) with the average rate of 75 per 100,000 for those treated in the hospital. An estimate of cases occurring in remote islands might bring the rate for the whole French Polynesia around 94 per 100,000. NFSB was more prevalent in females; rates for both genders were highest in the age group 25-35 years and 15-24 years. The main suicide method was drug poisoning by psychotropic drugs. The most frequent psychiatric disorder was mood disorder (45.3\%); however, $26 \%$ of subjects had no 'major' psychiatric disorders, with $14.5 \%$ without a psychiatric diagnosis or only reactive disorders (F43-11.7\%). There was a high prevalence of previous NFSB (52.1\%).

Limitations: Study includes only NFSB seeking medical help from the biggest hospital in the country. Conclusion: Suicide prevention activities specific to the findings and the socio-cultural context of French Polynesia should be considered.
\end{abstract}

(c) 2015 Elsevier B.V. All rights reserved.

\section{Introduction}

Tahiti, Bora Bora and the so-called wider 'Pacific island Blue Continent' are often considered paradise in the imagination of Westerners. This Eden-like image was created in the tales and writings of early European explorers (e.g., Cook, Bougainville), who discovered these friendly-populated islands. This myth, later reinforced by travelling writers (e.g., Segalen, Stevenson), makes it

\footnotetext{
* Correspondence to: Centre Hospitalier de Polynésie Française (CHPF), Département de Psychiatrie, BP 1640, 98713 Papeete,Tahiti, French Polynesia. Fax: +689 40484725 .

E-mail address: amadeo@mail.pf (S. Amadéo).
}

difficult to study the apparently paradoxical presence of suicidal behaviours in this region, the latter often being denied or minimised by the 'outside' people, as well as by the indigenous people themselves, who sometimes think of it as a purely 'imported' phenomenon.

Given the lack of regular, systematic and reliable data in the Pacific region (including French Polynesia), in 2005 the World Health Organisation (WHO) held a regional meeting in Manila to coordinate activities counteracting the reportedly increased burden of suicide in the Western Pacific region. In response to recommendations made at this meeting, a project called "Suicidal Trends in the At-Risk Territories" (START) Study was launched. The WHO/START Study represents the first coordinated international 
approach to suicide research and prevention in the region with a long-term aim to encourage the development of national suicide prevention strategies. The WHO/START Study comprises four components, described in details elsewhere (De Leo et al., 2009); some results have been presented (De Leo et al., 2013).

Following past recommendations from WHO collaborating studies, the WHO/START Study uses the term "non-fatal suicidal behaviours" (NFSB) which refers to "a non-habitual act with a nonfatal outcome that the individual, expecting to, or taking the risk to die or to inflict bodily harm, initiated and carried out with the purpose of bringing about wanted changes" (De Leo et al., 2006, p. 14). It is important to note that intent to die is often difficult to measure due to the ambivalence of a suicidal person; according to this definition, intent to die is not necessary considering there can be other types of intentions ('wanted changes').

The current article focuses on the results of the monitoring of non-fatal suicidal behaviour (NFSB) in French Polynesia, therefore the main aims of the paper are (1) to analyse the characteristics of NFSBs, such as gender, age, method of NFSB, marital and professional status, psychiatric disorder and potential triggers; and (2) to compare the socio-demographic characteristics of persons with NFSB to the general population.

\section{Methods}

\subsection{Data collection}

Information on NFSB was systematically collected on all persons admitted to the Emergency Department of the French Polynesia Hospital (Centre Hospitalier de Polynésie Française, CHPF) after self-harming behaviour, over a period of 2008-2010. Events were defined as "non-fatal suicidal behaviour" on the basis of the outcomes of the WHO/Multicentre Study on Suicidal Behaviour as indicated above (De Leo et al., 2006). It is important to note that this definition includes all self-harming behaviours, whether suicidal intent was present or not during the act.

The local study team who collected the data consisted of a psychiatrist ( $\mathrm{CI}$ of the study SA), three psychologists, an epidemiologist and students.

The questionnaire was translated into French and Tahitian, back translated into English and tested on 20 participants recruited in the Emergency Department of the CHPF. The protocol used in the WHO/START study for its monitoring phase (Component 1 ) is similar to that used in the WHO/Multisite Intervention Study on Suicidal Behaviours (SUPRE-MISS) (Fleischmann et al., 2005). The START questionnaire covers socio-demographic data, information of the current NFSB (method, potential triggers), and a series of variables related to clinical information (e.g. psychiatric diagnosis, alcohol and drug use). The psychiatric diagnosis was made by the psychiatrist who treated the patient following his and the psychologists' clinical judgement following the criteria of International Classification of Diseases ver 10 (ICD-10).

The ethics committee of French Polynesia approved the survey (CEPF, Avis No. 29, Jan 11, 2007) and the study was implemented between 1 January 2008 and 31 December 2010.

General population data was obtained from the 2012 census available at the Institut de la Statistique de Polynésie Française (http://www.ispf.pf).

\subsection{Statistical analysis}

Statistical analysis was performed using IBM SPSS Statistics 22. To make comparison, odds ratios (OR) with 95\% confidence intervals $(95 \% \mathrm{CI})$ were calculated. With small numbers (fewer than 5) Fisher's exact test was applied. In order to compare suicide rates in different groups Rate Ratios (RR) with 95\% CIs were calculated. A probability level of 0.05 was considered as significant.

\section{Results}

Between 2008 and 2010, there were 556 presentations of NFSB (also referred to as 'episodes') by 515 persons at the Emergency Department (ED) of the CHPF (presentation/persons ratio: 1.08). During the study period, 27 subjects 'attempted' two times (5.2\%), 4 subjects three times $(0.8 \%)$ and 2 subjects four times $(0.4 \%)$.

The START questionnaire was filled in at each presentation. Examination of the register of admissions at the ED for cases of NFSB identified that 20 episodes were not included in the analyses for each year due to momentary unavailability of staff. With an annual average of approximately 185 persons (205 episodes) presenting with NFSB at CHPF, the estimated mean rate of NFSB presenting at ED is 79.4 per 100,000 persons.

There were 382 female presentations by 350 persons (presentation/persons ratio 1.09) and 173 male presentations by 164 persons (presentation/persons ratio 1.05). Female to male persons ratio was 2.13 . There was one NFSB episode by a transsexual person who is not included in the analysis by gender in this article. Fig. 1 presents NFSB rates per 100,000 by gender and age groups for population aged 10 years and over. Rates of NFSB by persons for both genders are highest in the age group 25-35 years followed closely by the age group 15-24 years; however, the prevalence of NFSB by age groups was highest for younger age group (15-24 years) followed closely by the age group $25-34$ years (female $-34 \%$ vs $33.1 \%$; male $-32.9 \%$ vs $32.3 \%$ ). After the age of 35 years NFSB rates and prevalence drop.

Table 1 shows primary and secondary psychiatric diagnoses (ICD-10) of persons at the time of their first NFSB episode during the study period. It was not possible to diagnose 45 persons $(8.7 \%)$ as a psychiatrist was not available. An absence of primary diagnosis was noted in $14.5 \%$ of subjects, a proportion similar for both genders ( $14.4 \%$ for males and $14.6 \%$ for females). Therefore, we used 'not having a diagnosis' as the reference category for calculating odds ratios to compare males and females. The most frequent diagnoses were mood disorders (45.3\%), and while this was more common in females ( $48.1 \%$ vs $39.2 \%$ ), it did not reach statistical significance when compared to those 'not having a diagnosis' (Table 1). The second most frequent diagnoses for both genders were personality disorders (15\% for males and $13.3 \%$ for females). This was followed by anxiety and depressive reaction disorders (F43): $13.3 \%$ for females, $8.5 \%$ for males. The diagnosis of addictive disorders was significantly more frequent in males $(9.8 \%$ vs $2.2 \%$; $\mathrm{OR}=4.48,95 \% \mathrm{CI}=1.60=12.56$ ). It is important to note that psychotic disorders were present in $4.3 \%$ of the persons with NFSB, being significantly more common in males compared to

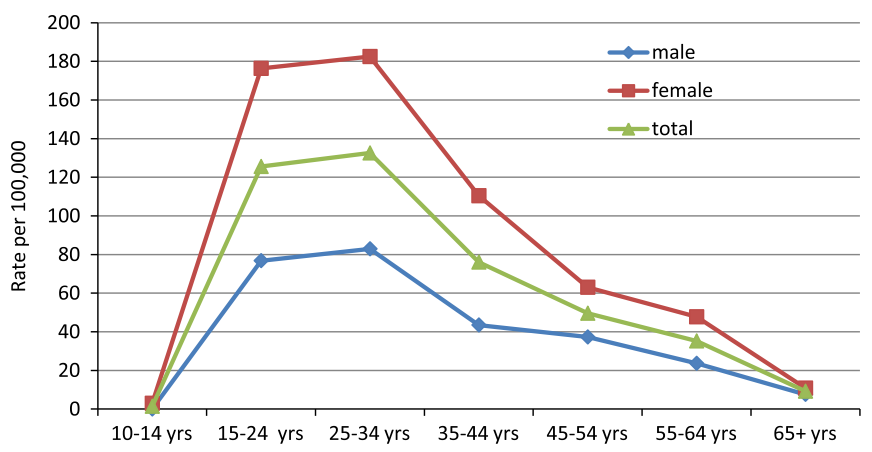

Fig. 1. Rates of NFSB for persons presenting to the ED of the CHPF in 2008-2010 (age at the time of their first attempt for those with more than one attempt). 
Table 1

Psychiatric diagnoses of NFSB population in French Polynesia (diagnosis at their first attempt for those with multiple attempts).

\begin{tabular}{|c|c|c|c|c|c|c|c|c|c|}
\hline Psychiatric disorders & $\begin{array}{l}\text { All p } \\
N\end{array}$ & $\%$ & $\begin{array}{l}\text { Male } \\
N\end{array}$ & $\%$ & $\begin{array}{l}\text { Fema } \\
N\end{array}$ & $\%$ & OR & $\begin{array}{l}95 \% \mathrm{C} \\
\mathrm{L} \mathrm{CI}\end{array}$ & $\mathrm{H} \mathrm{CI}$ \\
\hline \multicolumn{10}{|l|}{ Primary diagnosis } \\
\hline Addictive disorders (F10-F19) & 22 & 4.7 & 15 & 9.8 & 7 & 2.2 & 4.48 & 1.60 & 12.56 \\
\hline Psychotic disorders (F20-F29) & 20 & 4.3 & 12 & 7.8 & 8 & 2.5 & 3.14 & 1.12 & 8.77 \\
\hline Mood disorder (F30-F39) & 213 & 45.3 & 60 & 39.2 & 152 & 48.1 & 0.83 & 0.46 & 1.49 \\
\hline Anxiety disorders and phobias (F40-F41) & 24 & 5.1 & 7 & 4.9 & 17 & 5.4 & 0.86 & 0.31 & 2.38 \\
\hline Anxiety and depressive reaction disorders (F43) & 55 & 11.7 & 13 & 8.5 & 42 & 13.3 & 0.65 & 0.29 & 1.44 \\
\hline Other diagnoses (incl F50, F91, F98) & 3 & 0.6 & 1 & 0.7 & 2 & 0.6 & NA & & \\
\hline Personality disorders (F60) & 65 & 13.8 & 23 & 15.0 & 42 & 13.3 & 1.15 & 0.56 & 2.35 \\
\hline Without diagnosis & 68 & 14.5 & 22 & 14.4 & 46 & 14.6 & 1 & & \\
\hline \multicolumn{10}{|l|}{ Secondary diagnosis } \\
\hline Addictive disorders (F10-F12) & 23 & 4.9 & 10 & 6.5 & 13 & 4.1 & 1.68 & 0.71 & 3.95 \\
\hline Psychotic disorders (F20-F22-F23-F25) & 4 & 0.9 & 3 & 2.0 & 1 & 0.3 & NA & & \\
\hline Mood disorder (F30) & 9 & 1.9 & 3 & 2.0 & 6 & 1.9 & 1.09 & 0.27 & 4.45 \\
\hline Anxiety disorders and phobias (F40) & 26 & 5.5 & 6 & 3.9 & 20 & 6.3 & 0.66 & 0.26 & 1.68 \\
\hline Anxiety and depressive reaction disorders (F43) & 2 & 0.4 & 0 & 0 & 2 & 0.6 & NA & & \\
\hline Other diagnoses (incl F42, F50) & 2 & 0.4 & 1 & 0.7 & 1 & 0.3 & NA & & \\
\hline Personality disorders (F60) & 57 & 12.1 & 21 & 13.7 & 35 & 11.1 & 1.31 & 0.73 & 2.36 \\
\hline Without diagnosis & 347 & 73.8 & 109 & 71.2 & 238 & 75.3 & 1 & & \\
\hline
\end{tabular}

Missing (unknown) $=45(8.7 \%)$.

Bolded results indicate significance level 0.05 .

Table 2

NFSB in French Polynesia: characteristics of suicidal behaviours.

\begin{tabular}{|c|c|c|c|c|c|c|c|c|c|}
\hline \multirow[t]{2}{*}{ Characteristics } & \multicolumn{2}{|c|}{ All persons } & \multicolumn{2}{|c|}{ Male } & \multicolumn{2}{|c|}{ Female } & \multirow[t]{2}{*}{ OR } & \multicolumn{2}{|c|}{$95 \% \mathrm{CI}$} \\
\hline & $N$ & $\%$ & $N$ & $\%$ & $N$ & $\%$ & & L CI & $\mathrm{HCI}$ \\
\hline \multicolumn{10}{|l|}{ Suicide method (first) ${ }^{*}$} \\
\hline Medications and drugs (X60-X64) & 354 & 63.8 & 82 & 47.4 & 271 & 71.1 & 0.37 & 0.25 & 0.53 \\
\hline Pesticides and other chemicals (X66-X69) & 24 & 4.3 & 7 & 4.0 & 17 & 4.5 & 0.90 & 0.37 & 2.20 \\
\hline Hanging ( X70) & 93 & 16.8 & 51 & 29.5 & 42 & 11.0 & 3.37 & 2.14 & 5.33 \\
\hline Cutting (X78-X79) & 45 & 8.1 & 17 & 9.8 & 28 & 7.3 & 1.37 & 0.73 & 2.58 \\
\hline Firearms (X72-X74) & 1 & 0.2 & 0 & 0.0 & 1 & 0.3 & \multicolumn{3}{|c|}{$p=1.000$ (Fisher ex test) } \\
\hline Other methods & 38 & 6.8 & 16 & 9.2 & 22 & 5.8 & 1.66 & 0.85 & 3.25 \\
\hline \multicolumn{10}{|l|}{ Potential triggers (yes answers, multiple allowed) } \\
\hline Relationship problems (with partner) & 373 & 68.6 & 122 & 72.2 & 251 & 67.1 & 1.27 & 0.85 & 1.90 \\
\hline Family problems (with parents) & 186 & 34.0 & 62 & 36.3 & 123 & 32.8 & 1.17 & 0.80 & 1.70 \\
\hline Family problems (with children) & 61 & 11.0 & 9 & 5.7 & 52 & 14.3 & 0.36 & 0.17 & 0.75 \\
\hline Problems with social relationships & 74 & 13.7 & 22 & 13.3 & 51 & 13.7 & 0.97 & 0.56 & 1.65 \\
\hline Illness/somatic handicap & 49 & 9.0 & 18 & 10.7 & 31 & 8.3 & 1.32 & 0.72 & 2.43 \\
\hline Psychiatric disorders (mental illness/mental symptoms) & 131 & 24.0 & 37 & 21.8 & 93 & 24.9 & 0.84 & 0.55 & 1.30 \\
\hline Unemployment & 60 & 11.1 & 22 & 13.3 & 37 & 9.9 & 1.39 & 0.79 & 2.44 \\
\hline Addictive disorders (alcohol, drugs) & 82 & 15.0 & 31 & 18.3 & 51 & 13.6 & 1.43 & 0.88 & 2.33 \\
\hline Legal problems & 28 & 5.0 & 13 & 7.7 & 15 & 4.0 & 2.01 & 0.93 & 4.32 \\
\hline Financial problems & 60 & 11.1 & 19 & 11.3 & 40 & 10.7 & 1.07 & 0.60 & 1.90 \\
\hline Physical abuse & 79 & 14.4 & 25 & 14.6 & 53 & 14.1 & 1.04 & 0.62 & 1.74 \\
\hline Psychological abuse & 87 & 15.9 & 24 & 14 & 62 & 16.6 & 0.92 & 0.49 & 1.37 \\
\hline Sexual assault & 86 & 15.8 & 15 & 8.8 & 70 & 18.8 & 0.42 & 0.23 & 0.75 \\
\hline Other & 106 & 19.5 & 38 & 22.4 & 68 & 18.2 & 1.29 & 0.83 & 2.02 \\
\hline
\end{tabular}

Bolded results indicate significance level 0.05 .

${ }^{*}$ One case unknown (excluded from analysis).

*** Number of missing values varies between $1.8 \%$ up to $5.9 \%$.

females (7.8\% vs 2.5\%; Table 2). Secondary diagnoses were present in $26.2 \%$ of persons, $28.8 \%$ for males and $24.7 \%$ for females, respectively (Table 1 ). Personality disorders were the most common secondary diagnoses, similarly in both genders $(13.7 \%$ in males and $11.1 \%$ in females). Including both primary and secondary diagnoses, a personality disorder diagnosis was present in $26 \%$ of persons presenting with NFSB $(28.8 \%$ of males and $24.4 \%$ of females).

Over half of people $(52.1 \%)$ presenting with NFSB had history of previous suicidal episodes. Although this was more frequent in females, it did not reach statistical significance (47.5\% for males, $54.2 \%$ for females; $\mathrm{OR}=0.77,95 \% \mathrm{CI}=0.53-1.12$ ).

Table 2 presents suicide method (the first method recorded up to three methods were recorded) and triggers/events related to the episode of the NFSB (this includes all 556 episodes). The most common method was drug intoxication (X60-X64-63.8\%), with psychotropic medications (X61) being the most frequent (36.6\%) followed by hanging (X70-16.8\%) and cutting (X78-X79-8.1\%). It is important to note that cutting was present in $11.7 \%$ of episodes (including second and third methods). Females used poisoning 
Table 3

Socio-demographic characteristics of START NFSB population versus General Population (2012 census) in French Polynesia.

\begin{tabular}{|c|c|c|c|c|c|c|c|c|c|c|c|c|c|c|c|c|c|c|}
\hline & \multicolumn{3}{|c|}{ All persons } & \multirow{3}{*}{$\mathrm{RR}$} & & & \multicolumn{3}{|c|}{ Male } & \multirow{3}{*}{$\mathrm{RR}$} & & & \multicolumn{2}{|c|}{ Female } & \multirow{3}{*}{ Rate* } & \multirow{3}{*}{$\mathrm{RR}$} & \multirow{2}{*}{\multicolumn{2}{|c|}{$95 \% \mathrm{CI}$}} \\
\hline & $N$ & $\%$ & Rate* & & \multicolumn{2}{|c|}{$95 \% \mathrm{CI}$} & $N$ & $\%$ & Rate* & & \multicolumn{2}{|c|}{$95 \% \mathrm{CI}$} & $N$ & $\%$ & & & & \\
\hline & & & & & $\mathrm{L}$ & $\mathrm{H}$ & & & & & $\mathrm{L}$ & $\mathrm{H}$ & & & & & $\mathrm{L}$ & $\mathrm{H}$ \\
\hline \multicolumn{19}{|l|}{ Marital status ( $>15$ years) } \\
\hline Single & 160 & 32.3 & 93.3 & 1.26 & 1.03 & 1.53 & 54 & 35.1 & 52.2 & 1.14 & 0.80 & 1.62 & 106 & 31.2 & 156.1 & 1.55 & 1.22 & 1.97 \\
\hline Married/De facto & 300 & 60.6 & 75.4 & 1 & & & 90 & 58.4 & 45.8 & 1 & & & 209 & 61.5 & 102.0 & 1 & & \\
\hline Widowed & 4 & 0.8 & 17.5 & 0.24 & 0.08 & 0.65 & 1 & 0.6 & 17.7 & $* *$ & & & 3 & 0.9 & 17.5 & $* *$ & & \\
\hline Divorced/Seprated & 31 & 6.3 & 309.2 & 4.17 & 2.82 & 6.11 & 9 & 5.8 & 208.6 & 4.55 & 2.15 & 9.31 & 22 & 6.5 & 385.2 & 3.81 & 2.40 & 6.01 \\
\hline \multicolumn{19}{|l|}{ Professional status ( $>15$ years) } \\
\hline Employed (incl part time) & 261 & 54.1 & 97.3 & 1 & & & 96 & 62.7 & 61.9 & 1 & & & 165 & 50.3 & 145.9 & 1 & & \\
\hline Unemployed & 95 & 19.7 & 127.2 & 1.31 & 1.03 & 1.66 & 29 & 19.0 & 70.1 & 1.13 & 0.73 & 1.74 & 65 & 19.8 & 195.1 & 1.34 & 0.99 & 1.80 \\
\hline Full-time student & 70 & 14.5 & 124.5 & 1.28 & 0.97 & 1.68 & 15 & 9.8 & 56.9 & 0.92 & 0.51 & 1.62 & 55 & 16.8 & 184.3 & 1.26 & 0.92 & 1.73 \\
\hline Retired & 7 & 1.5 & 9.3 & 0.10 & 0.04 & 0.21 & 2 & 1.3 & 4.8 & $* *$ & & & 5 & 1.5 & 14.8 & 0.10 & 0.03 & 0.26 \\
\hline Other (incl home makers, disabled) & 48 & 10.0 & 35.9 & 0.37 & 0.27 & 0.52 & 11 & 7.2 & 24.2 & 0.39 & 0.20 & 0.42 & 37 & 11.3 & 41.9 & 0.29 & 0.20 & 0.42 \\
\hline
\end{tabular}

Marital status missing $=21(4 \%)$

Employment status missing $=33$ (6.4\%).

Bolded results indicate significance level 0.05 .

* Rates are calculated per 100,000 persons using 2012 FP Census information.

${ }^{* *}$ Not calculated due too small numbers.

significantly more frequently than males ( $47.4 \%$ vs $71.1 \%$; $O R=0.37$, $95 \% \mathrm{CI}=0.25-0.53$ ). Males used hanging more often than females $(29.5 \%$ vs. $11 \%$; OR=3.37, $95 \% \mathrm{CI}=2.14-5.33)$.

The most frequent precipitating factor of NFSB was represented by relationship problems (68.6\%), followed by family problems with parents or children (45\%), various psychological traumas such as physical and psychological abuse (30.3\%), psychiatric disorders (24\%), and sexual assault (15.8\%) (Table 2). Often, multiple reasons were reported for a single NFSB episode. The only significant difference by gender was identified for family problems with children, which was more frequent in females (5.7\% for males, $14.3 \%$ for females; $\mathrm{OR}=0.36,95 \% \mathrm{CI}=0.17-0.75$ ).

Table 3 presents the main socio-demographic characteristics marital and employment status-of the 515 persons by gender. Rates per 100,000 were calculated using the general population of French Polynesia (according to the 2012 Census of the Institute of Statistics of French Polynesia; Institut de la Statistique de Polynésie Française, ISPF). Rate ratios (RR) with $95 \% \mathrm{CI}$ were also presented using married/de facto as a references category for marital status. Being divorced was a significant risk factor for both genders compared to married/de facto (for males $\mathrm{RR}=4.55,95 \% \mathrm{CI}=2.15$ 9.31; for females $\mathrm{RR}=3.81,95 \% \mathrm{CI}=2.40-6.01$ ). Being single was a risk factor for females $(\mathrm{RR}=1.55,95 \% \mathrm{CI}=1.22-1.97)$ and was also significant when both genders were combined together $(R R=1.26$, $95 \% \mathrm{CI}=1.03-1.53)$. Number of widow(er)s was small and RR was calculated only for all persons, it showed significantly lower risk compared to married/de facto ( $R R=0.24,95 \% \mathrm{CI}=0.08-0.65$ ). Rates of NFSB were highest in the unemployed group (Table 3), and rate ratio was significantly higher when compared to the employed group (used as reference category) ( $R R=1.31,95 \%$ $\mathrm{CI}=1.03-1.66)$. However, risk of NFSB was significantly lower in retired persons $(\mathrm{RR}=0.10,95 \% \mathrm{CI}=0.04-0.21)$ and in group 'other' (including mainly homemakers) $(\mathrm{RR}=0.37,95 \% \mathrm{CI}=0.27-0.52$ ).

\section{Discussion}

There were no official data on Non-Fatal Suicidal Behaviour (NFSB) in French Polynesia and others Polynesian islands; in light of this, the current study appears of particular interest. In French Polynesia, the only estimates of the prevalence of suicidal behaviours were based on two medical dissertations, both concerning individuals admitted at the same hospital of the current study (Boyer, 2000; Garcia, 2006). Compared to a crude rate of 58.5 per 100,000 in 1988-1999 (the period observed in the first medical dissertation - Boyer (2000)), and to 79.5 per 100,000 in 2005 (reported in the second dissertation - Garcia (2006)), the current study shows a relatively similar rate to that of the 2005 analysis (79.4). However, it is important to note that NFSB rate for the whole French Polynesia is higher. There are approximately 50 persons admitted with NFSB to the four peripheral hospitals of French Polynesia annually (not taking into account the health care facilities existing in the 76 small inhabited islands). Therefore a more correct estimate of the annual number of NFSB for all of French Polynesia would be 255 cases annually, which equals to a crude rate of 98 NFSB cases per 100,000 persons. In any case, all French Polynesian studies show that subjects engaging in NFSB were more frequently females (approximately two thirds), which is similar to what happens in most countries (WHO, 2014). Similarly to other countries, NFSB rates and prevalence was highest in the younger age groups between 15 and 34 years of age.

Intentional drug poisoning (X60-X64) was used in almost 2/ 3rd of NFSB cases, with psychotropic drugs (X61) being most common. This was similar to Australia and Hong Kong, which were other WHO/START study sites. However, other Pacific Islands showed high level of pesticides (e.g. Fiji) and analgesics (e.g. Vanuatu) (De Leo et al., 2013). It was also similar to the findings from European countries participating in the WHO/EURO Multicentre Study on Suicidal behaviours (Schmidtke et al., 2004). This may be an indication of the strong European influence on French Polynesia. Methods of suicide and non-fatal suicidal behaviours vary between the countries depending on availability and acceptability. Restricting access to means has been found to be the most effective method in suicide prevention (WHO, 2014) and could be considered in reducing NFSB in French Polynesia.

Over half of persons presenting with NFSB had history of previous suicidal behaviour (52.1\%), which indicates the importance of monitoring and follow-up of suicidal subjects in addition to usual care (such as through telephone contacts), in order to reduce repetition of NFSB. This intervention showed reduction in number of suicides in the SUPRE-MISS study (Fleischmann et al., 2008) but not in number of NFSB (Bertolote et al., 2010); it gave some promising results in French Polynesia in the frames of the START study (Amadéo et al., 2015). 
Relationship problems with partners and family problems/ conflicts with parents or children were the most frequent triggers of NFSB. Different life events such as family conflicts and separation have been found to be the trigger of suicide attempts (Arensman and Kerhof, 2004) and suicide (Kolves et al., 2006). Pompili et al. (2011) found that recent life events were significant precipitants of suicide attempts when comparing suicide attempters to other psychiatric inpatients in their sample in Italy. Similarly to the WHO/EURO Multicentre Study on Suicidal Behaviours, females with NFSB in the current study had a significantly higher prevalence of sexual assault compared to males (Arensman and Kerhof, 2004). Difficulties in dealing with life events (problems) indicate that some preventive approaches could be introduced starting from early age, such as problem solving skills, education of good parenting and couple life, but also anger management, including control of impulsiveness and acting out. This highlights the importance of primary prevention programs (e.g. in schools).

Despite only $24 \%$ of episodes were considered to be directly triggered by mental health problems, $71.7 \%$ had a diagnosable psychiatric disorder (by ICD-10). In addition $13.8 \%$ had a personality disorder as a primary diagnosis and $14.5 \%$ had no psychiatric diagnosis. It is also important to note that $11.7 \%$ presented only brief anxiety and depression reactions (F43). These results are comparable to those of Pompili et al. (2011), who found that $82.9 \%$ of suicide attempters were admitted to the Division of Psychiatry in Parma (Italy). Nevertheless, in total, approximately a quarter of the subjects in the current study had none or very mild psychopathological symptoms. This could be explained by high prevalence of NFSB in age groups 15-24 and 25-35 years, and there might be some cultural factors promoting some degree of acceptance of impulsive behaviour and acting out in younger age groups. Prolonged adolescence called "taure'are'a" (Metcalfe, 2004) often justifies a behaviour characterised by emotional immaturity that facilitates impulsive and uncontrolled reactions in sometimes trivial situations, e.g. after a single offensive word or gaze, and without the presence of any psychiatric illness or personality disorder. This is also comparable to Micronesia were suicidal behaviours is very high in youth and often considered as impulsive acts with a high proportion related to anger (Ran, 2007).

\subsection{Implications for prevention}

Epidemiological surveillance of suicidal behaviours should possibly continue in the form of monitoring of suicidal behaviours. This could permit timely interventions and appropriate and culturally sensitive preventive initiatives. Like in other countries, implementing pluralistic suicide prevention approaches is required. In French Polynesia, they could be based on strong NGOs and religious communities. SOS Suicide, created in 2001, set up a crisis line in 2006 and has developed, since 2008, WHO preventive actions (such as the SUPRE and the START Study) with the support of local authorities (Amadéo, 2010).

In order to prevent suicidal behaviours, both fatal and nonfatal, it seems that multiple interventions have to be implemented in a coordinated manner, possibly controlling single contribution of each intervention in light of choosing those inititives offering economic sustainability. Skills training in depression and suicidal behaviour for General Practitioners, as well as gatekeepers (such as police officers, social workers, teachers, priests etc.) and public awareness campaigns providing information on symptoms of depression and their treatment apper to be important step to rapidly undertake at universal level. Reducing access to means (e.g. pesticides, controlled sale of medications) and improved quality of media reports on suicide appear also applicable interventions. Crisis HelpLines, new technologies (internet-based self-treatment of depression, telemedicine, etc.) (Chen et al., 2010), wider provision of cognitive behaviour therapy for people who have engaged in suicidal behaviour, support for those bereaved by suicide are also initiatives thar should be available in French Polynesia in a more stuructured manner at the selective and indicated levels. Addressing alcohol and drug abuse, improving treatment for people with depression, anxiety disorders, and those with severe psychatric disorders or have experienced sexual and physical abuse, are also absolute imperative for the country. Attention should be paid in the direction of structuring academic programs in suicide prevention; in addition, post-graduate education and training (university diplomas) for health professionals, and growing research and evaluation interests are initiative that should be developed in parallel. Given the particular geographical and cultural context, all strategies should be interwined with the vigent traditional medicine principles and care, together with religious and spiritual beliefs and attitudes.

\subsection{Limitations}

The main limitation concerns the nature of data collection, which includes only NFSB seeking medical help from the biggest hospital in the country. Therefore, results obtained provide the dimension of those NFSB treated in hospital and not the prevalence of NFSB at community level. In addition, some cases were not monitored due to temporary unavailability of staff, and for some other cases information was missing (below 10\%). Considering the nature of the study - monitoring of NFSB at hospital level, there was no control group and population census data was available only for limited number of variables. Due to small numbers in some categories (e.g., widows, retired) statistical power was also limited for calculating rates.

\section{Conclusions}

The monitoring part of the worldwide START study has offered opportunities for better knowledge and understanding of the characteristics of NFSB in French Polynesia. Current analysis identified that the main characteristics of suicide attempters (NFSB), admitted to the emergency room of the Hospital Centre of French Polynesia, were young females, with history of past NFSB, who had problems in their relationships and overdosed with medications (analgesics or psychotropic drugs). Most frequent psychiatric disorders were anxiety and depressive disorders and Post-Traumatic Stress Disorder; a remarkable percentage of subjects did not present any mental disorders.

Growing a research culture would be particularly important, especially considering the social and economic factors influencing suicidal behaviours and the rapid modernisation of this splendid country, with the impacts of increased globalisation and tourism.

\section{Conflict of interest \\ Nothing to declare.}

\section{Contributors}

SA and DDL designed the study. SA, AM, MR, PF were involved in data collection. KK and NLN conducted data analyses. Authors SA, LJ, KK and DDL wrote the first draft of the manuscript. All authors contributed to and have approved the final manuscript.

\section{Role of the funding source}

We would like to acknowledge grant from the EPAP-government agency (Ministry of Health of French Polynesia). 


\section{Acknowledgements}

We would like to thank, for moral support, the successive governments of French Polynesia and the High Commissioner (French Government Representative). We would like to acknowledge support from the Hospital CHPF Management, Dr Yves Petit and Dr Guillaume Garcia (Department of Psychiatry), Dr Fabrice Jeannette and Dr Nathalie Lecordier, Patricia Page, and Kamel Boussouak (Emergency Department) and the Department of Public Health in French Polynesia for their approval and technical assistance, and members of SOS Suicide for their assistance with the survey (Olivier De Longeaux, Germaine David, Annie Tuheaiva, Jean Vaimeho). Thank you to Sebastien Merceron from the ISPF for providing additional data of 2012 French Polynesia Census.

\section{References}

Amadéo, S., 2010. Quel rôle pour les associations dans la prevention du suicide, Ed Médecine-Sciences. Flammarion, Paris.

Arensman, E., Kerhof, A., 2004. Negative life events and non-suicidal behaviours. In: DeLeo, D., Bille-Brahe, U., Kerkhof, A., Schmidtke, A. (Eds.), Suicidal Behaviour: Theories and Research Findings. Hogrefe \& Huber Publishers, Gottingen, pp. 93-109.

Amadéo, S., Rereao, M., Malogne, A., Favro, P., Nguyen, L.N., Jehel, L., Milner, A., Kolves, K., De Leo, D., 2015. Testing brief intervention and phone contact among subject with suicidal behaviour: A randomized controlled trial in French Polynesia in the frame of the WHO/START study. Ment. Illn. 7, 5818, 10.4081/mi. 2015.5818.

Bertolote, J.M., Fleischmann, A., De Leo, D., Philips, M., Botega, N., Vijayakumar, L., De Silva, D., Schlebusch, L., Nguyen, V.T., Sisask, M., Bolhari, J., Wasserman, D., 2010. Repetition of suicide attempts: data from emergency care setting in five culturally different low-and middle- income countries participating in the WHO SUPRE-MISS Study. Crisis 31, 194-201.

Boyer, E., 2000. Suicides et tentatives de suicide en Polynésie française. Thèse de médecine, Bordeaux.

Chen, H., Mishara, B.,L., Liu, X., 2010. A pilot study of mobile telephone message interventions with suicide attempters in China. Crisis 31, 109-112.

De Leo, D., Burgis, S., Bertolote, J.M., Kerkhof, A.J.M., Bille-Brahe, U., 2006. Definitions of suicidal behaviour. Lessons learned from the WHO/EURO Multicentre
Study on Suicidal behaviour. Crisis 27, 4-15.

De Leo, D., Milner, A., Wang, X., 2009. Suicidal behavior in the Western Pacific region: characteristics and trends. Suicide Life Threat Behav. 39, 72-81.

De Leo, D., Milner, A., Fleischmann, A., Bertolote, J., Collings, S., Amadeo, S., Chan, S. Yip, P., Huang, Y., Saniel, B., Lilo, F., Lilo, C., David, A.M., Benavente, B., Nadera, D., Pompili, M., Kolves, K.E., Kolves, K., Wang, X., 2013. The WHO START Study: Suicidal behaviors across different areas of the world. Crisis 34, 156-163.

Fleischmann, A., Bertolote, J.M., De Leo, D., Botega, N., Phillips, M., Sisask, M., Vijayakumar, L., Malakouti, K., Schlebusch, 1, Da Silva, D., Van Tuong, N., Wasserman, D., 2005. Characteristics of attempted suicides seen in emergency-care settings of general hospitals in eight low- and middle-income countries. Psychol. Med. 35, 1467-1474.

Fleischmann, A., Bertolote, J.M., Wasserman, D., De Leo, D., Bolhari, J., Botega, N., Da Silva, D., Phillips, M., Vijayakumar, L., Varnik, A., Schlebusch, 1, Thanh, H.T.T., 2008. Effectiveness of brief intervention and contact for suicide attempters: a randomized controlled trial in five countries. Bull. World Health Organ. 86, 703-709.

Garcia, G., 2006. Tentatives de suicide en Polynésie française. Thèse de Médecine, Marseille.

Kolves, K., Varnik, A., Schneider, B., Fritze, J., Allik, J., 2006. Recent life events: a case-control study in Tallinn and Frankfurt. Soc. Sci. Med. 62, 2887-2896.

Metcalfe, R., 2004. Transit of Venus. Huia Publishers, New Zeland.

Pompili, M., Innamorati, M., Szanto, K., Di Vittorio, C., Conwell, Y., Lester, D., Tatarelli, R., Girardi, P., Amore, M., 2011. Life events as precipitants of suicide attempts among first-time suicide attempters, repeaters, and non-attempters. Psychiatry Res. 186, 300-305.

Ran, M.S., 2007. Suicide in Micronesia: a systematic review. Prim. Psychiatry 14, $80-87$.

Schmidtke, A., Bille-Brahe, U., DeLeo, D., Kerkhof, A., Lohr, C., Weinacker, B., Batt, A Creper, P., Fekete, S., Grad, O., Haring, C., Hawton, K., van Heeringer, C., Hjelmeland, H., Lonnquist, J., Michel, K., Pommereau, X., Querejeta, I., Salander Renberg, E., Temesvary, B., Vanirk, A., Wasserman, D., Rutz, W., 2004. Sociodemographic characteristics of suicide attempters in Europe. In: Schmidtke, A Bille-Brahe, U., DeLeo, D., Kerkhof, A. (Eds.), Suicidal Behaviour in Europe: Results from the WHO/EURO Multicetre Study. Hogrefe \& Huber Publishers, Gottingen, pp. 29-43.

World Health Ogranization, 2014. Preventing Suicide: A Global Imperative. WHO, Geneva. 